\title{
An Algorithm (LaD) for Monitoring Childbirth in Settings Where Tracking All Parameters in the World Health Organization Partograph Is Not Feasible: Design and Expert Validation
}

Michael S Balikuddembe ${ }^{1,2}$, MBChB, MMed; Peter K Wakholi ${ }^{3}$, MSc, PhD; Nazarius M Tumwesigye ${ }^{4}$, PhD, MSc, MA; Thorkild Tylleskar ${ }^{1}, \mathrm{MD}, \mathrm{PhD}, \mathrm{MA}$

\footnotetext{
${ }^{1}$ Center for International Health, University of Bergen, Bergen, Norway

${ }^{2}$ Division of Maternal and Foetal Medicine, Mulago Specialised Women and Newborn Hospital, Mulago Hospital, Kampala, Uganda

${ }^{3}$ School of Computing and Information Technology, Makerere University Kampala, Kampala, Uganda

${ }^{4}$ Department of Epidemiology and Biostatistics, Makerere University School of Public Health, Kampala, Uganda
}

\section{Corresponding Author:}

Thorkild Tylleskar, MD, PhD, MA

Center for International Health

University of Bergen

PO Box 7800

Bergen, 5020

Norway

Phone: 4748074410

Email: Thorkild.Tylleskar@uib.no

\section{Abstract}

Background: After determining the key childbirth monitoring items from experts, we designed an algorithm (LaD) to represent the experts' suggestions and validated it. In this paper we describe an abridged algorithm for labor and delivery management and use theoretical case to compare its performance with human childbirth experts.

Objective: The objective of this study was to describe the $\mathrm{LaD}$ algorithm, its development, and its validation. In addition, in the validation phase we wanted to assess if the algorithm was inferior, equivalent, or superior to human experts in recommending the necessary clinical actions during childbirth decision making.

Methods: The LaD algorithm encompasses the tracking of 6 of the 12 childbirth parameters monitored using the World Health Organization (WHO) partograph. It has recommendations on how to manage a patient when parameters are outside the normal ranges. We validated the algorithm with purposively selected experts selecting actions for a stratified sample of patient case scenarios. The experts' selections were compared to obtain pairwise sensitivity and false-positive rates (FPRs) between them and the algorithm.

Results: The mean weighted pairwise sensitivity among experts was 68.2\% (SD 6.95; 95\% CI 59.6-76.8), whereas that between experts and the $\mathrm{LaD}$ algorithm was $69.4 \%$ (SD 17.95; 95\% CI 47.1-91.7). The pairwise FPR among the experts ranged from $12 \%$ to $33 \%$ with a mean of $23.9 \%$ (SD 9.14; 95\% CI 12.6-35.2), whereas that between experts and the algorithm ranged from $18 \%$ to $43 \%$ (mean 26.3\%; SD 10.4; 95\% CI 13.3-39.3). The was a correlation (mean 0.67 [SD 0.06]) in the actions selected by the expert pairs for the different patient cases with a reliability coefficient $(\alpha)$ of .91 .

Conclusions: The LaD algorithm was more sensitive, but had a higher FPR than the childbirth experts, although the differences were not statistically significant. An electronic tool for childbirth monitoring with fewer WHO-recommended parameters may not be inferior to human experts in labor and delivery clinical decision support.

(JMIR Med Inform 2021;9(5):e17056) doi: 10.2196/17056

\section{KEYWORDS}

algorithm; software validation; childbirth monitoring; WHO partograph 


\section{Introduction}

From the late 20th century, there were concerted efforts to improve pregnancy outcomes, with the World Health Organization (WHO) partograph being the main labor monitoring tool used globally [1-3]. Increasing and easing of childbirth monitoring have been at the forefront of strategies for better maternal and newborn outcomes [4-6]. A spiraling increase in the number of caesarean sections due to prolonged labor led to research that challenged the cervical dilatation rates in the partograph [7-9]. Doubt arose on the validity of the partograph and intrapartum guidelines with calls for their re-evaluation $[5,6,10]$. Calls for more evidence-based care at birth led to increased research for more practical labor monitoring guidelines and tools [7,11-13].

In 2015, the American college of Obstetricians and the Society for Maternal-Fetal Medicine issued new guidelines on labor monitoring [14]. Later, the WHO released new recommendations on partograph use including calls for more research on the most appropriate paper-based or electronic tool to aid childbirth decision making [12]. Before any electronic decision support can be developed, an algorithm is needed outlining which decisions to take at each potential situation along the birth of a child. The algorithm is also preceded by a decision on which input variables to use is needed. Among the problems with the WHO partograph was a large number of variables to register and it was regarded as labor intensive and unpractical for low-resource settings $[4,15]$. We studied the labor monitoring tool expectations of childbirth experts in Africa to generate consensus on the most important parameters to monitor during birth in low-resource settings $[16,17]$. The findings included a reduction in the WHO-modified partograph items and several suggestions on changing the frequency of monitoring the labor items. The experts also expressed a need to adopt the recommendation for raising the starting point of the partograph from $4 \mathrm{~cm}$ of cervical dilatation.

In this paper, we describe the labor and delivery (LaD) algorithm, its development, and validation. In the validation we wanted to know if the algorithm is inferior, equivalent, or superior to human experts in recommending the necessary clinical actions during childbirth decision making.

\section{Methods}

\section{Overview}

We used the maternity experts' recommendations and literature findings to develop an alternative algorithm for labor and delivery monitoring (the $\mathrm{LaD}$ algorithm). We conducted a preliminary validation of its logic before fully implementing it. Because of lack of a gold standard against which to compare the logic, we compared it against opinions of experts in childbirth monitoring. Comparison of results from medical devices against experts is increasingly seen as the better alternative when no gold standard exists and decisions are highly dependent on opinions or anecdotal evidence [18-21].

\section{Development of the LaD Algorithm}

From our earlier studies [16,17], the key parameters to monitor in childbirth were the fetal heart rate, amniotic fluid, cervical dilatation, uterine contractions, maternal blood pressure, and pulse rate. The suggested monitoring intervals ranged from 30 minutes to 4 hours. These are 6 of the 12 parameters in the WHO-modified partograph [22]. We used these recommendations and literature on the progress and outcomes of monitoring various childbirth items to generate a parameter list and monitoring intervals to include in the algorithm. Our main adjustment to the experts' suggestions was replacing the maternal pulse with second-stage tracking of the fetal station (a surrogate for fetal descent).

We used our acumen on labor progress and its monitoring process to draw the LaD algorithm using the Microsoft Visio 2013. It was revised to the layout shown in Figure 1. It shows the parameters to monitor at evidence-based time intervals.

For the algorithm to run on a computing device, we translated it into a recursive (ie, a problem is divided into subproblems of the same type. The solution to the problem is devised by combining the solutions obtained from the simpler parts of the problem) logic with 1152 possible patient scenarios and key decision support actions. Any abnormality in labor monitoring parameters is independently managed (as per local guidelines) and the final labor management decision is based on the success or failure in managing the subabnormalities. It is this logic that we validated with another group of childbirth experts. 
Figure 1. The $\mathrm{LaD}$ algorithm for monitoring labor and delivery.

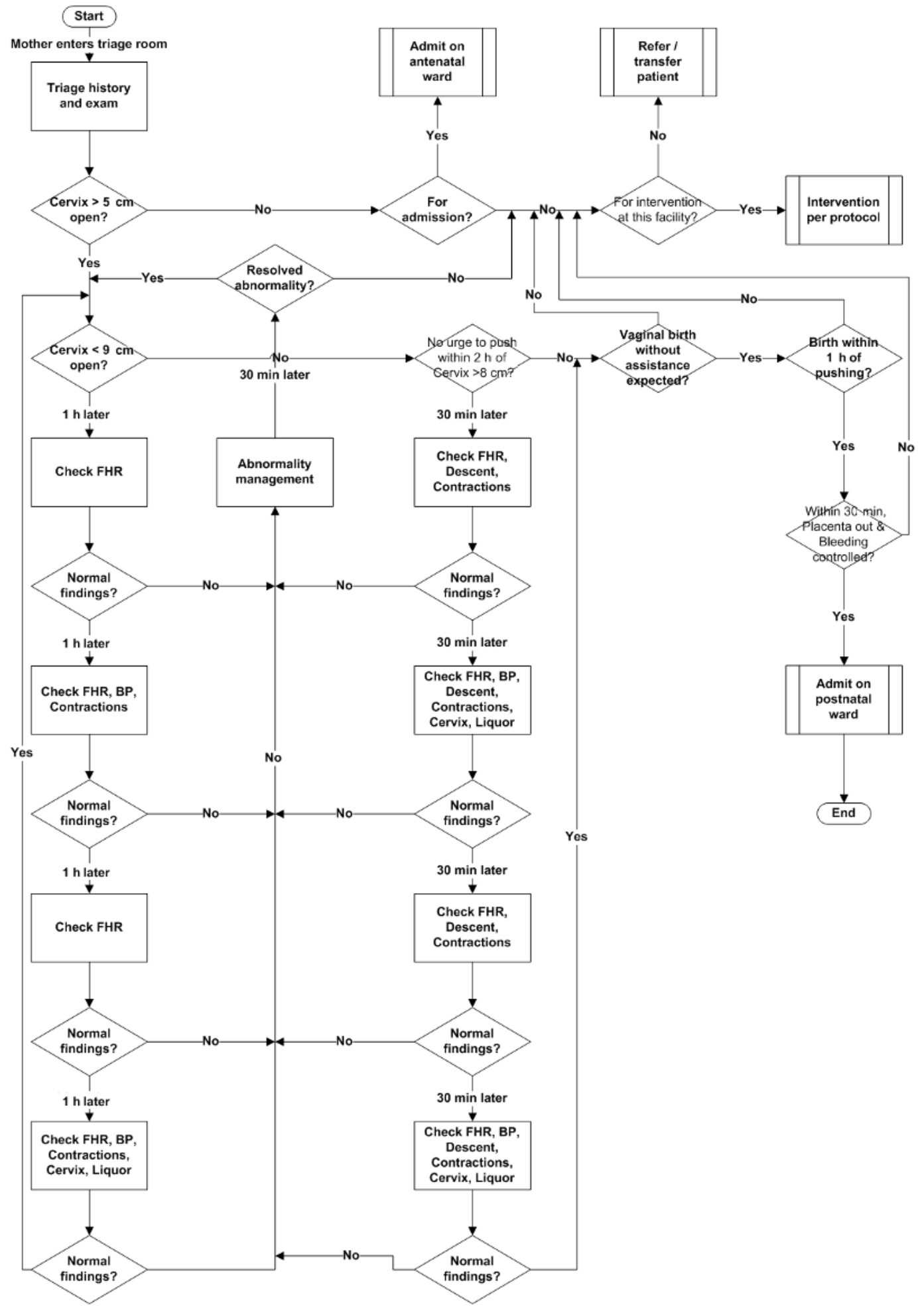

\section{Validation of the LaD Algorithm}

Between January and February 2019, 5 purposively selected childbirth care experts (E1, E2, E3, E4, and E5) independently answered a survey questionnaire covering 6 patient case scenarios (P1, P2, P3, P4, P5, and P6). The 5 experts had a mean experience of 17 years (SD 5.8 years) in medical practice and an obstetric career length ranging from 5 to 17 years (mean 10.6 years [SD 5.1 years]). Most worked in a teaching hospital, with their highest education level ranging from a master's degree to a Doctor of Philosophy (Table 1). 
Table 1. Summary characteristics of experts who participated in validation.

\begin{tabular}{|c|c|c|c|c|c|c|}
\hline Characteristics & Expert 1 & Expert 2 & Expert 3 & Expert 4 & Expert 5 & Mean (SD) \\
\hline Experience as a doctor (years) & 12 & 16 & 11 & 23 & 23 & $17(5.8)$ \\
\hline Experience as an obstetrician (years) & 6 & 11 & 5 & 14 & 17 & $10.6(5.1)$ \\
\hline $\begin{array}{l}\text { Number of times expert selected actions } \\
\text { in the } 5 \text { scenarios (maximum } 80 \text { ) }\end{array}$ & 36 & 34 & 44 & 35 & 46 & $39(5.6)$ \\
\hline Highest level of medical education & Master's degree & Master's degree & $\mathrm{PhD}$ candidate & Master's degree & $\mathrm{PhD}$ & - \\
\hline Primary workplace & Military hospital & Medical school & Medical school & National hospital & Medical school & - \\
\hline
\end{tabular}

The case scenarios were taken from childbirth scenarios in the algorithm using stratified sampling. The cases were stratified using the amniotic fluid status into 3 strata: membranes intact, amniotic fluid clear, and amniotic fluid opaque or foul smelling. An online random number generator [23] was used to randomly select 2 cases from each stratum. The questionnaire had 15 labor-related conditions and 22 actions to consider. Each expert was allowed to select up to 16 of the 22 actions per case scenario, hence a maximum of 80 actions across 5 cases. The actions recommended by the algorithm for the study case scenarios were used to assess it.

We explained the survey procedure to the human experts before asking them to study the case scenarios and the accompanying set of possible actions to consider for managing each case. The expert would then recommend the most important actions for each case scenario given its conditions. The algorithm also recommended actions to the same cases based on results of an earlier study of a larger group of experts and literature. Experts in this study, however, were not aware of the algorithm nor other experts' action recommendations. They were invited to suggest possible modifications to the actions list for clarity and to provide better decision support for the case conditions.

We analyzed data to determine the unadjusted and weighted interexpert pairwise sensitivity [18,24], false-positive rates (FPRs), and reliability coefficients. Pairwise sensitivity was calculated for each pair of experts; for instance E3-E4 is the sensitivity of E4 with respect to E3 as reference. The sensitivity of the $\mathrm{LaD}$ algorithm versus each human reviewer $(\mathrm{E}-\mathrm{LaD})$ was also calculated to determine how LaD-human expert scores compare with interhuman expert pairwise (E-E) scores. FPRs were calculated for the unadjusted scores. The weight assigned to an action was determined by the number of experts that selected that action for a given case scenario. That is, an action weighed 1.0 if all 5 experts selected it as important, 0.6 if 3 selected it, and 0 if none selected it. Therefore, the weights were assigned after data entry. We compared the LaD algorithm scores with averages of the human pairwise scores for each case and across all scenarios. To rank the algorithm and human experts, we compared the lower border for the $95 \% \mathrm{CI}$ of the mean sensitivity and the upper border of its mean FPR confidence interval with corresponding values for the experts. A larger number of the lower limit border for the sensitivity confidence interval and a smaller number of the upper limit for the FPR confidence interval meant a superior rank [21].

\section{Results}

\section{Overview of Case Scenarios}

A total of 5 of the 6 case scenarios were managed by all experts while the sixth was completed by 2 experts. The experts articulated that the noncompleted case was similar to another they had answered and saw no big difference in general management.

As indicated in Table 2, for the 5 case scenarios together, the experts selected an average of 39 actions of a possible 80 . Across the experts, case scenarios 1 and 5 received most actions with an average of 11 each, whereas case scenario 2 needed the fewest actions at 5. From the unadjusted data, unlike the experts, the $\mathrm{LaD}$ algorithm had most actions for case scenario 3 , but there was no difference in the weighted scores. 
Table 2. Number of actions selected per patient (actual and adjusted values).

\begin{tabular}{|c|c|c|c|c|c|c|c|c|c|c|}
\hline \multirow[t]{2}{*}{ Evaluator } & \multicolumn{2}{|l|}{$\mathrm{P} 1^{\mathrm{a}}$} & \multicolumn{2}{|l|}{$\mathrm{P} 2$} & \multicolumn{2}{|l|}{ P3 } & \multicolumn{2}{|l|}{$\mathrm{P} 4$} & \multicolumn{2}{|l|}{ P5 } \\
\hline & Action & $\begin{array}{l}\text { Adjusted } \\
\text { value }\end{array}$ & Action & $\begin{array}{l}\text { Adjusted } \\
\text { value }\end{array}$ & Action & $\begin{array}{l}\text { Adjusted } \\
\text { value }\end{array}$ & Action & $\begin{array}{l}\text { Adjusted } \\
\text { value }\end{array}$ & Action & $\begin{array}{l}\text { Adjusted } \\
\text { value }\end{array}$ \\
\hline $\mathrm{E} 1^{\mathrm{b}}$ & 9 & 7.2 & 5 & 3.4 & 5 & 4 & 6 & 3.4 & 11 & 8 \\
\hline E2 & 8 & 6.8 & 5 & 3.4 & 8 & 4.8 & 5 & 3.6 & 8 & 6 \\
\hline E3 & 12 & 7.4 & 4 & 2.8 & 6 & 3.4 & 9 & 5.2 & 13 & 9.4 \\
\hline E4 & 11 & 7.8 & 5 & 2.6 & 7 & 3.6 & 4 & 1.4 & 8 & 5 \\
\hline E5 & 13 & 8.8 & 5 & 3.4 & 5 & 3.6 & 9 & 4.6 & 14 & 9.6 \\
\hline Mean (SD) & $10.6(2.1)$ & $7.6(0.8)$ & $4.8(0.4)$ & $3.1(0.4)$ & $6.2(1.3)$ & $3.9(0.6)$ & $6.6(2.3)$ & $3.6(1.5)$ & $10.8(2.8)$ & $7.6(2.0)$ \\
\hline $\begin{array}{l}\text { Labor and delivery } \\
\text { algorithm (LaD) }\end{array}$ & 8 & 4.6 & 7 & 3.4 & 12 & 5.4 & 7 & 3.8 & 8 & 5.6 \\
\hline
\end{tabular}

${ }^{\mathrm{b}} \mathrm{P}$ : patient case scenario.

${ }^{\mathrm{a}} \mathrm{E}$ : expert.

\section{Pairwise Sensitivity and FPRs for the Experts and the LaD Algorithm}

The interrater pairwise sensitivity for the experts and the $\mathrm{LaD}$ algorithm is shown in Figure 2. The mean for unadjusted pairwise sensitivity among experts (E-E) for all cases was 57.2\% (SD 7.86; 95\% CI 47.4-67.0), whereas the weighted mean sensitivity was $68.2 \%$ (SD 6.95; 95\% CI 59.6-76.8). The difference between these means was significant (SD 11.0; 95\% CI 2.8-21.2, $P=.01$ ). With reference to the experts, the mean sensitivity scores of the $\mathrm{LaD}$ algorithm $(\mathrm{E}-\mathrm{LaD})$ were $62.6 \%$ (SD 17.01; 95\% CI 41.5-83.7) and 69.4\% (SD 17.95; 95\% CI 47.1-91.7) before and after adjustment, respectively. The difference of 6.8 in $\mathrm{E}-\mathrm{LaD}$ means the $95 \%$ CI of -14.9 to 28.5 was not statistically significant, $P=.32$ ). As shown in Figure 3, the weighted pairwise sensitivity for experts was significantly higher $(P=.02)$ and closer to the $\mathrm{LaD}$ sensitivity than the unadjusted scores, especially when $\mathrm{E} 4$ was the reference expert. The algorithm was more sensitive than E1, E4, and E5, but less sensitive than E3.

For the 5 patient cases, the average FPR of experts ranged from $12 \%$ to $33 \%$ with a mean of $23.9 \%$ (SD 9.14; $95 \%$ CI 12.6-35.2), whereas that for the $\mathrm{E}-\mathrm{LaD}$ ranged from $18 \%$ to $43 \%$ with a mean of $26.3 \%$ (SD 10.43; 95\% CI 13.3-39.3). Table 3 shows that case 2 was an outlier (in left tail) for the expert-to-expert pairwise false-positive scores and case 3 was an outlier (right tail) for the expert-to-algorithm FPR scores. 
Figure 2. The interrater pairwise sensitivity scores for the five cases.
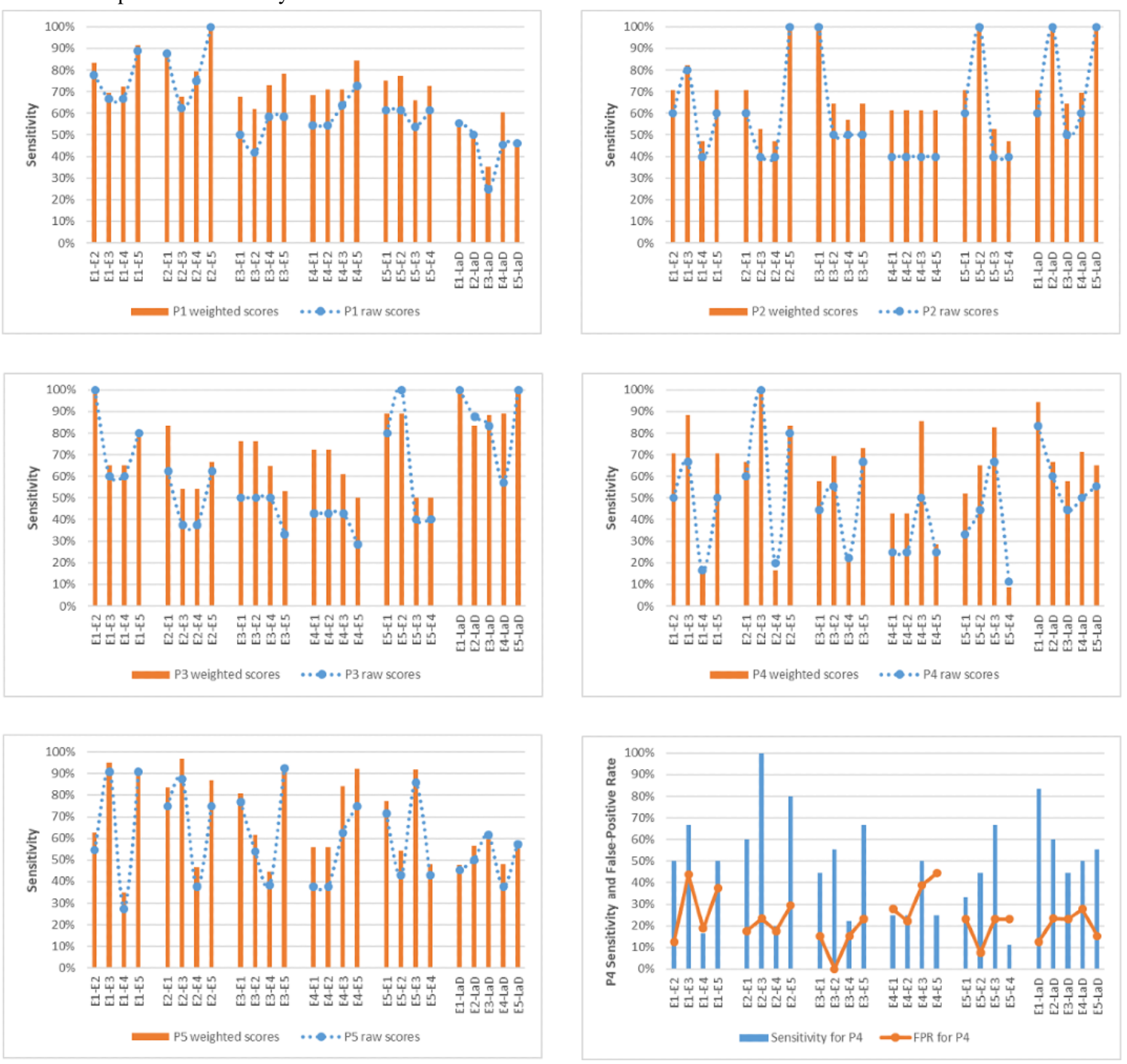

Figure 3. Comparison of the overall weighted and unadjusted pairwise sensitivity scores.

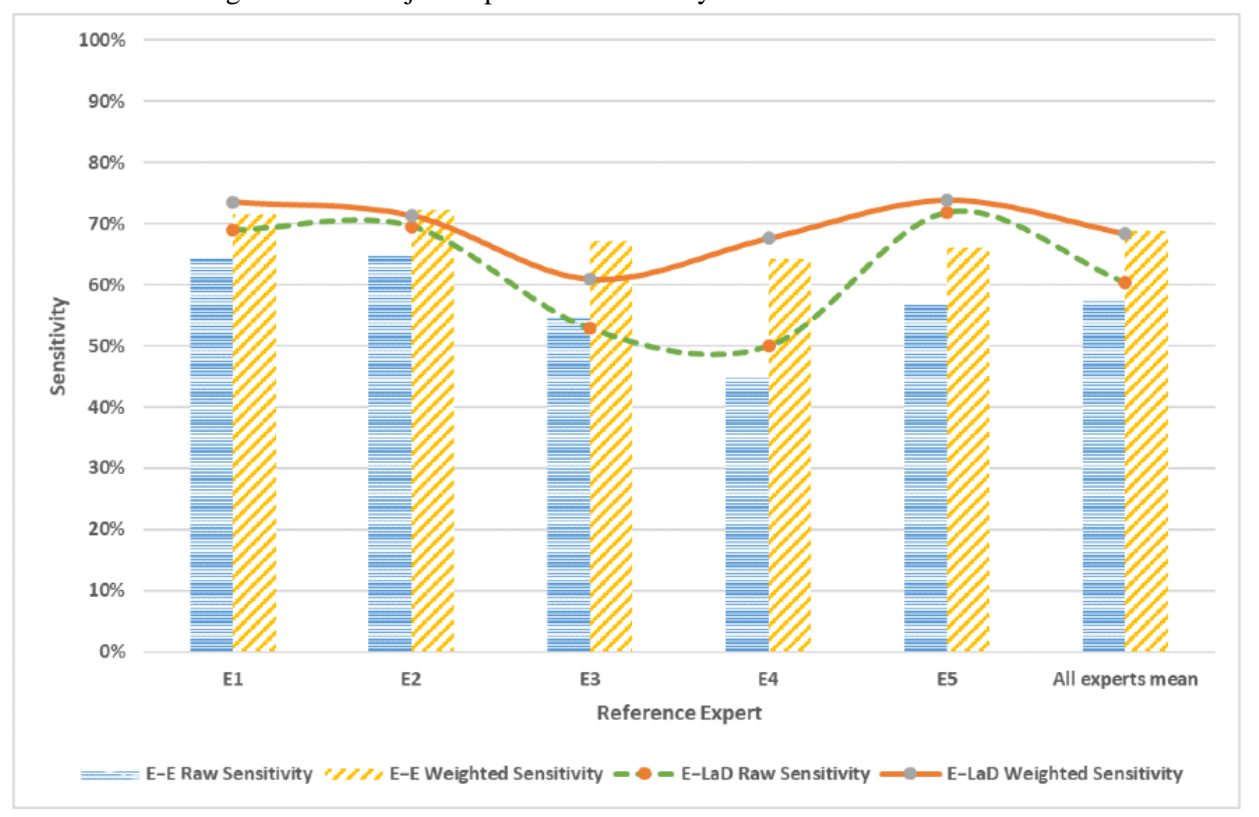


Table 3. Pairwise sensitivity and false-positive rates of experts and the labor and delivery $(\mathrm{LaD})$ algorithm.

\begin{tabular}{|c|c|c|c|c|c|c|c|c|}
\hline Comparisons & $\mathrm{P} 1^{\mathrm{a}}$ & $\mathrm{P} 2$ & P3 & $\mathrm{P} 4$ & P5 & Mean (SD) & $95 \%$ CI for mean & $\begin{array}{l}\text { CI for difference } \\
\text { of } 2 \text { means }\end{array}$ \\
\hline $\begin{array}{l}\mathrm{E}-\mathrm{E}^{\mathrm{b}} \text { pairwise sensitivity: un- } \\
\text { adjusted }\end{array}$ & 65.9 & 56.5 & 55.0 & 45.6 & 62.8 & $57.2(7.86)$ & 47.4 to 67.0 & -11.0 to 21.8 \\
\hline $\begin{array}{l}\text { E-LaD pairwise sensitivity: } \\
\text { unadjusted }\end{array}$ & 44.4 & 74.0 & 85.6 & 58.7 & 50.3 & $62.6(17.01)$ & 41.5 to 83.7 & \\
\hline $\begin{array}{l}\text { E-E pairwise sensitivity: } \\
\text { weighted }\end{array}$ & 75.9 & 67.2 & 68.6 & 57.3 & 71.9 & $68.2(6.95)$ & 59.6 to 76.8 & -15.7 to 18.1 \\
\hline $\begin{array}{l}\text { E-LaD pairwise sensitivity: } \\
\text { weighted }\end{array}$ & 49.3 & 80.8 & 92.1 & 71.0 & 54.0 & $69.4(17.95)$ & 47.1 to 91.7 & \\
\hline $\begin{array}{l}\text { E-E pairwise } \mathrm{FPR}^{\mathrm{c}} \text { for an ac- } \\
\text { tion }\end{array}$ & 33.1 & 12.2 & 18.3 & 23.2 & 32.9 & $23.9(9.14)$ & 12.6 to 35.2 & -9.8 to 14.6 \\
\hline $\begin{array}{l}\text { E-LaD pairwise FPR for an } \\
\text { action }\end{array}$ & 30.2 & 19.7 & 43.0 & 20.5 & 18.3 & $26.3(10.43)$ & 13.3 to 39.3 & \\
\hline $\begin{array}{l}\text { E-E pairwise sensitivity for } \\
\text { an action: unadjusted }\end{array}$ & 65.9 & 56.5 & 55.0 & 45.6 & 62.8 & $57.2(7.86)$ & 47.4 to 67.0 & 2.8 to 21.2 \\
\hline $\begin{array}{l}\text { E-E pairwise sensitivity for } \\
\text { an action: weighted }\end{array}$ & 75.9 & 67.2 & 68.6 & 57.3 & 71.9 & $68.2(6.95)$ & 59.6 to 76.8 & \\
\hline $\begin{array}{l}\text { E-LaD pairwise agreement } \\
\text { for an action: unadjusted }\end{array}$ & 44.4 & 74.0 & 85.6 & 58.7 & 50.3 & $62.6(17.01)$ & 41.5 to 83.7 & -14.9 to 28.5 \\
\hline $\begin{array}{l}\text { E-LaD pairwise agreement } \\
\text { for an action: weighted }\end{array}$ & 49.3 & 80.8 & 92.1 & 71.0 & 54.0 & $69.4(17.95)$ & 47.1 to 91.7 & \\
\hline
\end{tabular}

${ }^{\mathrm{a}} \mathrm{P}$ : patient case scenario.

${ }^{\mathrm{b}} \mathrm{E}$ : expert.

${ }^{\mathrm{c}}$ FPR: false-positive rate.

\section{Determining the Rank of LaD Algorithm Among Human Experts}

The $95 \%$ CIs for the mean sensitivity scores of the algorithm and the human experts showed that the LaD algorithm had a higher upper limit before and after adjustment to the mean. By contrast, the lower limit of the confidence interval for the expert FPR mean was lower than that of the interval for the $\mathrm{LaD}$ algorithm mean. There was a positive correlation (mean $r$ selection of 0.67 [SD 0.06]) in the actions that the expert pairs selected for the different patient cases (Table 4) with a reliability coefficient close to $1(\alpha=.91)$. This meant that the study experts agreed on most actions necessary for the cases and the same actions were likely to be recommended by these or other experts for the given patient scenarios.
Finally, we needed to know whether the differences in the mean sensitivity and FPR of the LaD algorithm and human experts were significant. The difference in mean sensitivity was 5.4 (95\% CI -11.0 to 21.8 ) for the unadjusted means and $1.2(95 \%$ $\mathrm{CI}-15.7$ to $18.1, P=.57$ ) for the weighted means. Because both intervals crossed the null, there was no statistical difference in the sensitivity of the experts and algorithm. In addition, the mean FPR of the experts and the algorithm was not significantly different with a $95 \% \mathrm{CI}$ of -9.8 to $14.6(P=.69)$.

On the basis of these sensitivity and false-positive scores, we found no statistical difference between the $\mathrm{LaD}$ algorithm and human experts recommending actions to childbirth monitoring health workers. 
Table 4. Correlation and reliability coefficients of experts' choices of actions for the cases.

\begin{tabular}{|c|c|c|c|c|c|c|}
\hline \multirow[t]{2}{*}{ Comparisons } & \multicolumn{5}{|c|}{ Selection correlation coefficient of actions selected by experts for each case, $r^{\text {selectiona }}$} & \multirow{2}{*}{$\begin{array}{l}\text { Reliability coefficient, } \\
\alpha^{\mathrm{b}}\end{array}$} \\
\hline & $\mathrm{P} 1^{\mathrm{c}}$ & $\mathrm{P} 2$ & $\mathrm{P} 3$ & $\mathrm{P} 4$ & P5 & \\
\hline $\mathrm{E} 1-\mathrm{E} 2^{\mathrm{d}}$ & 0.857 & 0.706 & 0.913 & 0.686 & 0.722 & \\
\hline E1-E3 & 0.685 & 0.907 & 0.705 & 0.714 & 0.877 & \\
\hline E1-E4 & 0.703 & 0.538 & 0.685 & 0.275 & 0.443 & \\
\hline E1-E5 & 0.829 & 0.706 & 0.848 & 0.607 & 0.844 & .925 \\
\hline E2-E1 & 0.857 & 0.706 & 0.913 & 0.686 & 0.722 & \\
\hline E2-E3 & 0.649 & 0.583 & 0.644 & 0.832 & 0.772 & \\
\hline E2-E4 & 0.751 & 0.538 & 0.625 & 0.267 & 0.511 & \\
\hline E2-E5 & 0.879 & 1.000 & 0.770 & 0.737 & 0.685 & .923 \\
\hline E3-E1 & 0.685 & 0.908 & 0.705 & 0.713 & 0.876 & \\
\hline E3-E2 & 0.648 & 0.583 & 0.644 & 0.832 & 0.772 & \\
\hline E3-E4 & 0.720 & 0.593 & 0.629 & 0.445 & 0.613 & \\
\hline E3-E5 & 0.719 & 0.583 & 0.514 & 0.777 & 0.927 & .919 \\
\hline E4-E1 & 0.703 & 0.538 & 0.760 & 0.275 & 0.443 & \\
\hline E4-E2 & 0.751 & 0.538 & 0.626 & 0.268 & 0.511 & \\
\hline E4-E3 & 0.720 & 0.593 & 0.629 & 0.445 & 0.613 & \\
\hline E4-E5 & 0.782 & 0.538 & 0.500 & 0.158 & 0.664 & .861 \\
\hline E5-E1 & 0.829 & 0.706 & 0.843 & 0.607 & 0.844 & \\
\hline E5-E2 & 0.879 & 1.000 & 0.770 & 0.737 & 0.685 & \\
\hline E5-E3 & 0.719 & 0.583 & 0.514 & 0.777 & 0.926 & \\
\hline E5-E4 & 0.783 & 0.538 & 0.500 & 0.158 & 0.664 & .922 \\
\hline Mean (SD) & $0.757(0.073)$ & $0.669(0.159)$ & $0.687(0.129)$ & $0.550(0.237)$ & $0.706(0.152)$ & $.910(0.027)$ \\
\hline
\end{tabular}

${ }^{a} r^{\text {selection }}$ is an extension to Pearson $r=$ square root of (sensitivity AB $\times$ selectivity AB), where selectivity RT $=$ sensitivity TR. This is the selectivity for a test expert $\mathrm{T}$ against a reference expert $\mathrm{R}$.

${ }^{b} \alpha=k R /(1+[k-1] R)$, where $k$ is the number of experts and $\mathrm{R}$ is the average correlation of all expert pairs.

${ }^{\mathrm{c}} \mathrm{P}$ : patient case scenario.

${ }^{\mathrm{d}} \mathrm{E}$ : expert.

\section{Discussion}

\section{Principal Findings}

The search for an ideal labor and delivery monitoring decision support tool is ongoing and this study was one of many attempts to improve these tools. We have described the design of the $\mathrm{LaD}$ algorithm and validated it through comparison of its logic with human experts of childbirth monitoring. We found the algorithm to be equivalent in sensitivity and FPRs to experts with high reliability, that is, its action recommendations were close to the clinically "correct" ones. In clinical situations, lack of a gold standard against which to evaluate tools meant that traditional device validation tests were inappropriate and so childbirth experts had to act as the reference silver standard as in most types of clinical decision making [20,24]. Like Scheuer et al [21], we used the selection correlation coefficient $r^{\text {selection }}$ (an extension to Pearson $r$ ) because clinical experts often agree on many nonimportant actions for any patient case [18]. Most childbirth actions are not selected independent of one another, so our results would be less trustworthy if we used the kappa or pi statistics for measuring agreement. Likewise, we could not use Gwet AC statistic that necessitated assigning constant weights based on gold standards to parameters for all the patients, which would not be rational in our scenario [18,25]. The results of this study can be used to develop an abridged and more appropriate paper- or computer-based labor monitoring decision support tool that is less contentious than the WHO-modified partograph.

\section{Limitations}

The main limitations to this study are as follows: First, the low number of patient cases rated by the experts. Patient clinical scenarios have subtle or major differences that it would be virtually impossible to expect an exhaustive tool or validation. The cases were few, but each contained 22 actions to be considered; thus, the experts were not assessed on one case/condition per se, but on a sum of actions for each case and 
then the average of the 5. Therefore, the experts and algorithm were assessed on 110 instances summarized into 5 cases. This approach was similar to that used by Scheuer et al [21] who had over 5000 spike detections presented in under 40 scenarios [21]. Second, a total of 5 experts were not enough to tease out the effect of fast or slow actors when deciding to intervene in a clinical maternity setting. The fast actors tend to intervene too soon and so too much, whereas the slow actors intervene too late and so too late for good clinical outcomes, as expressed by Miller et al [26]. Third, the algorithm was based on suggestions from providers in low-income settings which are generally on the "too little, too late" side, and hence we expected the participants (E1, E4, and E5) to be more sensitive and E3 to be slower at acting. The strength of the pairwise sensitivity and the modified correlation we used is dampening the individual effect/biases of participants such that we still found no statistical differences between the group and the algorithm. Another limitation could have been our set of candidate actions from which experts selected. As was done by other researchers [18], we provided experts with candidate actions (from other studies) to encourage them to concentrate on relevant actions, but it could have hindered participants with divergent opinions from choosing their preferred actions. Following years of promoting the WHO partograph, some childbirth experts have got so engrained in it that any changes to its parameters could seem unfounded and unacceptable [27-29]. With these limitations in mind, we agreed that our validation results were preliminary and more assessments of the LaD algorithm would be done after its deployment and testing under more conditions.

\section{Conclusions}

The LaD algorithm was more sensitive but with a higher FPR than the childbirth experts, although the differences were not statistically significant. An electronic tool for childbirth monitoring with fewer parameters than those in the modified WHO partograph may not be inferior to human experts in labor and delivery clinical decision support.

\section{Acknowledgments}

We thank all participant experts for voluntarily sparing time to participate in the research.

\section{Authors' Contributions}

MB collected data and wrote the initial manuscript draft. All authors participated in proposal development and analysis of the data. All authors read and approved the final manuscript.

\section{Conflicts of Interest}

None declared.

\section{References}

1. Mutebi A. Why are mothers and babies still dying? Voices from the community and service providers. BMJ Open. (Suppl 1) 2015;5:61. [doi: 10.1136/bmjopen-2015-forum2015abstracts.61]

2. Wall SN, Lee AC, Carlo W, Goldenberg R, Niermeyer S, Darmstadt GL, et al. Reducing intrapartum-related neonatal deaths in low- and middle-income countries-what works? Semin Perinatol 2010 Dec;34(6):395-407. [doi: 10.1053/j.semperi.2010.09.009] [Medline: 21094414]

3. World Health Organization. World Health Organization partograph in management of labour. The Lancet 1994 Jun;343(8910):1399-1404. [doi: 10.1016/s0140-6736(94)92528-3]

4. Ollerhead E, Osrin D. Barriers to and incentives for achieving partograph use in obstetric practice in low-and middle-income countries: a systematic review. BMC Pregnancy Childbirth 2014 Aug 16;14(1):281 [FREE Full text] [doi: 10.1186/1471-2393-14-281] [Medline: 25132124]

5. Jeffery J, Hewison A, Goodwin L, Kenyon S. Midwives' experiences of performing maternal observations and escalating concerns: a focus group study. BMC Pregnancy Childbirth 2017 Sep 02;17(1):282 [FREE Full text] [doi: 10.1186/s12884-017-1472-8] [Medline: 28865442]

6. Yang F, Bohren MA, Kyaddondo D, Titiloye MA, Olutayo AO, Oladapo OT, et al. Healthcare providers' perspectives on labor monitoring in Nigeria and Uganda: A qualitative study on challenges and opportunities. Int J Gynaecol Obstet 2017 Dec 07;139 Suppl 1:17-26. [doi: 10.1002/ijgo.12379] [Medline: 29218726]

7. Neal JL, Lowe NK. Physiologic partograph to improve birth safety and outcomes among low-risk, nulliparous women with spontaneous labor onset. Med Hypotheses 2012 Feb;78(2):319-326 [FREE Full text] [doi: 10.1016/j.mehy.2011.11.012] [Medline: 22138426]

8. Neal JL, Lowe NK, Patrick TE, Cabbage LA, Corwin EJ. What is the slowest-yet-normal cervical dilation rate among nulliparous women with spontaneous labor onset? J Obstet Gynecol Neonatal Nurs 2010 Jul;39(4):361-369 [FREE Full text] [doi: 10.1111/j.1552-6909.2010.01154.x] [Medline: 20629924]

9. Romijn MSc A, Muijtjens Dr Ir AMM, de Bruijne Dr MC, Donkers Dr HHLM, Wagner Prof Dr C, de Groot Prof Dr CJM, et al. What is normal progress in the first stage of labour? A vignette study of similarities and differences between midwives and obstetricians. Midwifery 2016 Oct;41:104-109. [doi: 10.1016/j.midw.2016.08.006] [Medline: 27586088$]$ 
10. Oladapo OT, Souza JP, Fawole B, Mugerwa K, Perdoná G, Alves D, et al. Progression of the first stage of spontaneous labour: A prospective cohort study in two sub-Saharan African countries. PLoS Med 2018 Jan 16;15(1):e1002492 [FREE Full text] [doi: 10.1371/journal.pmed.1002492] [Medline: 29338000]

11. Debilina R, Mandal D, Sahana R, Mandal A, Chowdhury P, Kundu T. ETD - expected ?time? of delivery: a new simple clinical tool for management of labour. Int J Med Appl Sci 2015;4(4):51-57.

12. World Health Organization. WHO Recommendations: Intrapartum Care for a Positive Childbirth Experience. Geneva, Switzerland: WHO; 2018.

13. Souza JP, Oladapo OT, Bohren MA, Mugerwa K, Fawole B, Moscovici L, WHO BOLD Research Group. The development of a Simplified, Effective, Labour Monitoring-to-Action (SELMA) tool for Better Outcomes in Labour Difficulty (BOLD): study protocol. Reprod Health 2015 May 26;12(1):49 [FREE Full text] [doi: 10.1186/s12978-015-0029-4] [Medline: 26006758]

14. No authors listed. Obstetric care consensus no. 1: safe prevention of the primary cesarean delivery. Obstet Gynecol 2014 Mar;123(3):693-711. [doi: 10.1097/01.AOG.0000444441.04111.1d] [Medline: 24553167]

15. Bedwell C, Levin K, Pett C, Lavender DT. A realist review of the partograph: when and how does it work for labour monitoring? BMC Pregnancy Childbirth 2017 Jan 13;17(1):31 [FREE Full text] [doi: 10.1186/s12884-016-1213-4] [Medline: 28086823]

16. Balikuddembe M, Wakholi P, Tumwesigye N, Tylleskär T. Midwifery providers' preferences for a childbirth monitoring tool in low-income health units in Uganda. In: Ugon A, editor. Building Continents of Knowledge in Oceans of Data: The Future of Co-Created eHealth. Amsterdam, The Netherlands: IOS Press; 2018:456-460.

17. Balikuddembe MS, Tumwesigye NM, Wakholi PK, Tylleskär T. Expert perspectives on essential parameters to monitor during childbirth in low resource settings: a Delphi study in sub-Saharan Africa. Reprod Health 2019 Aug 05;16(1):119 [FREE Full text] [doi: 10.1186/s12978-019-0786-6] [Medline: 31382989]

18. Wilson S, Harner R, Duffy F, Tharp B, Nuwer M, Sperling M. Spike detection. I. Correlation and reliability of human experts. Electroencephalography and Clinical Neurophysiology 1996 Mar;98(3):186-198. [doi: 10.1016/0013-4694(95)00221-9]

19. Trautner BW, Bhimani RD, Amspoker AB, Hysong SJ, Garza A, Kelly PA, et al. Development and validation of an algorithm to recalibrate mental models and reduce diagnostic errors associated with catheter-associated bacteriuria. BMC Med Inform Decis Mak 2013 Apr 15;13(1):48 [FREE Full text] [doi: 10.1186/1472-6947-13-48] [Medline: 23587259]

20. Sharma NK, Pedreira C, Centeno M, Chaudhary UJ, Wehner T, França LGS, et al. A novel scheme for the validation of an automated classification method for epileptic spikes by comparison with multiple observers. Clin Neurophysiol 2017 Jul;128(7):1246-1254 [FREE Full text] [doi: 10.1016/j.clinph.2017.04.016] [Medline: 28531810]

21. Scheuer ML, Bagic A, Wilson SB. Spike detection: Inter-reader agreement and a statistical Turing test on a large data set. Clin Neurophysiol 2017 Jan;128(1):243-250 [FREE Full text] [doi: 10.1016/j.clinph.2016.11.005] [Medline: 27913148]

22. Vidyashri Kamath C, Nagarathna G, Sharanya S. Documentation of the modified WHO partograph during labour in a South Indian tertiary care hospital. jemds 2015 Oct 12;4(82):14415-14421. [doi: 10.14260/jemds/2015/2050]

23. Furey E. Random number and letter set generator. URL: www.calculatorsoup.com/calculators/statistics/number-generator. php [accessed 2021-04-11]

24. Teal CR, Haidet P, Balasubramanyam AS, Rodriguez E, Naik AD. Measuring the quality of patients' goals and action plans: development and validation of a novel tool. BMC Med Inform Decis Mak 2012 Dec 27;12(1):152 [FREE Full text] [doi: 10.1186/1472-6947-12-152] [Medline: 23270422]

25. Wongpakaran N, Wongpakaran T, Wedding D, Gwet KL. A comparison of Cohen's Kappa and Gwet's AC1 when calculating inter-rater reliability coefficients: a study conducted with personality disorder samples. BMC Med Res Methodol 2013 Apr 29;13(1):61 [FREE Full text] [doi: 10.1186/1471-2288-13-61] [Medline: 23627889]

26. Miller S, Abalos E, Chamillard M, Ciapponi A, Colaci D, Comandé D, et al. Beyond too little, too late and too much, too soon: a pathway towards evidence-based, respectful maternity care worldwide. The Lancet 2016 Oct;388(10056):2176-2192. [doi: 10.1016/s0140-6736(16)31472-6]

27. Fistula Care and Maternal Health Task Force: Revitalizing the Partograph: Does the Evidence Support a Global Call to Action?. URL: http://www.bettercaretogether.org/sites/default/files/resources/ EngenderHealth-Fistula-Care-Partograph-Meeting-Report-9-April-12.pdf [accessed 2016-11-04]

28. Kushwah B, Singh AP, Singh S. The partograph: an essential yet underutilized tool. jemds 2013 Jun 14;2(24):4373-4379. [doi: $10.14260 /$ jemds/849]

29. Cohen WR, Friedman EA. Perils of the new labor management guidelines. Am J Obstet Gynecol 2015 Apr;212(4):420-427. [doi: 10.1016/j.ajog.2014.09.008] [Medline: 25218127]

\section{Abbreviations}

FPR: false-positive rate

WHO: World Health Organization 
Edited by C Lovis; submitted 18.11.19; peer-reviewed by J Shen, O Abiodun-Ojo; comments to author 19.01.20; revised version received 29.04.20; accepted 04.05.20; published 27.05.21

Please cite as:

Balikuddembe MS, Wakholi PK, Tumwesigye NM, Tylleskar T

An Algorithm (LaD) for Monitoring Childbirth in Settings Where Tracking All Parameters in the World Health Organization Partograph Is Not Feasible: Design and Expert Validation

JMIR Med Inform 2021;9(5):e17056

URL: https://medinform.jmir.org/2021/5/e17056

doi: $\underline{10.2196 / 17056}$

PMID:

CMichael S Balikuddembe, Peter K Wakholi, Nazarius M Tumwesigye, Thorkild Tylleskar. Originally published in JMIR Medical Informatics (https://medinform.jmir.org), 27.05.2021. This is an open-access article distributed under the terms of the Creative Commons Attribution License (https://creativecommons.org/licenses/by/4.0/), which permits unrestricted use, distribution, and reproduction in any medium, provided the original work, first published in JMIR Medical Informatics, is properly cited. The complete bibliographic information, a link to the original publication on https://medinform.jmir.org/, as well as this copyright and license information must be included. 